\title{
Dating the geometric Nasca lines in the Peruvian desert
}

\author{
W.J. Rink ${ }^{1} \&$ J. Bartoll ${ }^{2}$
}

The Nasca lines are geoglyphs - arrays of stones forming geometric shapes constructed by ancient humans, the largest ones occupying areas of more than $1 \mathrm{~km}^{2}$. The authors used optically stimulated luminescence dating of quartz buried when the stone lines were constructed to give new dates for contexts associated with geoglyphs on high mesetas near Palpa. They conclude that the stone lines at sites at San Ignacio and Sacramento were constructed between AD 400 and 650. This suggests that they were made in the later part of the Early Intermediate Period by people of the Nasca culture.

Keywords: Nasca, geoglyph, optically stimulated luminescence, quartz

\section{Introduction}

The patterns of stone lines located between Nasca and Palpa, Peru (Figure 1) form geometric and biomorphic geoglyphs spread over an area of several hundred square kilometres of desert surface. The geometric examples occur as long straight lines, triangles, rectangles, trapezoids, spirals and zigzag forms, while the biomorphic features exhibit humanoid, animal and plant forms. They were reported by early Spanish explorers and then appeared in the archaeological literature as early as 1927 (Mejia Xesspe 1927). The lifelong work of the mathematician Maria Reiche made them known in public and initiated their broad scientific exploration (Reiche 1969). Most recent studies use modern methods of mapping and photogrammetry (Grun et al. 2000; Reindel et al. 2001, 2002). Theories about their purpose and use are still under discussion (Morrison 1978; Aveni 1990; Silverman \& Proulx 2002). Proposed explanations of their purpose include astronomical/calendrical objects, indicators for underground water, agricultural use, artistic expression, ceremonial sites, religious pathways and guideposts for desert travel.

Our research demonstrates that their origin can be ascribed to a two-stage process. First, humans built elongated stone heaps leaving behind areas free from larger stones, and then natural geological processes infilled the stone heaps with finer-grained sediment. A colour contrast can now be seen in aerial views, with the darker zones being the in-filled stone lines and undisturbed desert pavement, while the cleared areas show up as lighter areas.

Previous attempts to determine the age of the geoglyphs have not been conclusive. Wooden posts at the intersections of two different sets of lines have given uncalibrated ${ }^{14} \mathrm{C}$ dates of AD $525 \pm 80$ and $490 \pm 80$ (Bray 1992). Pottery fragments found around the lines

1 School of Geography and Geology, McMaster University, 1280 Main St. W., Hamilton, ON L8S 4K1, Canada (Email:rinkwj@mcmaster.ca)

2 Prussian Palaces and Gardens Foundation, Berlin-Brandenburg, Department of Conservation, P.O. Box 601462, 14414 Potsdam, Germany 


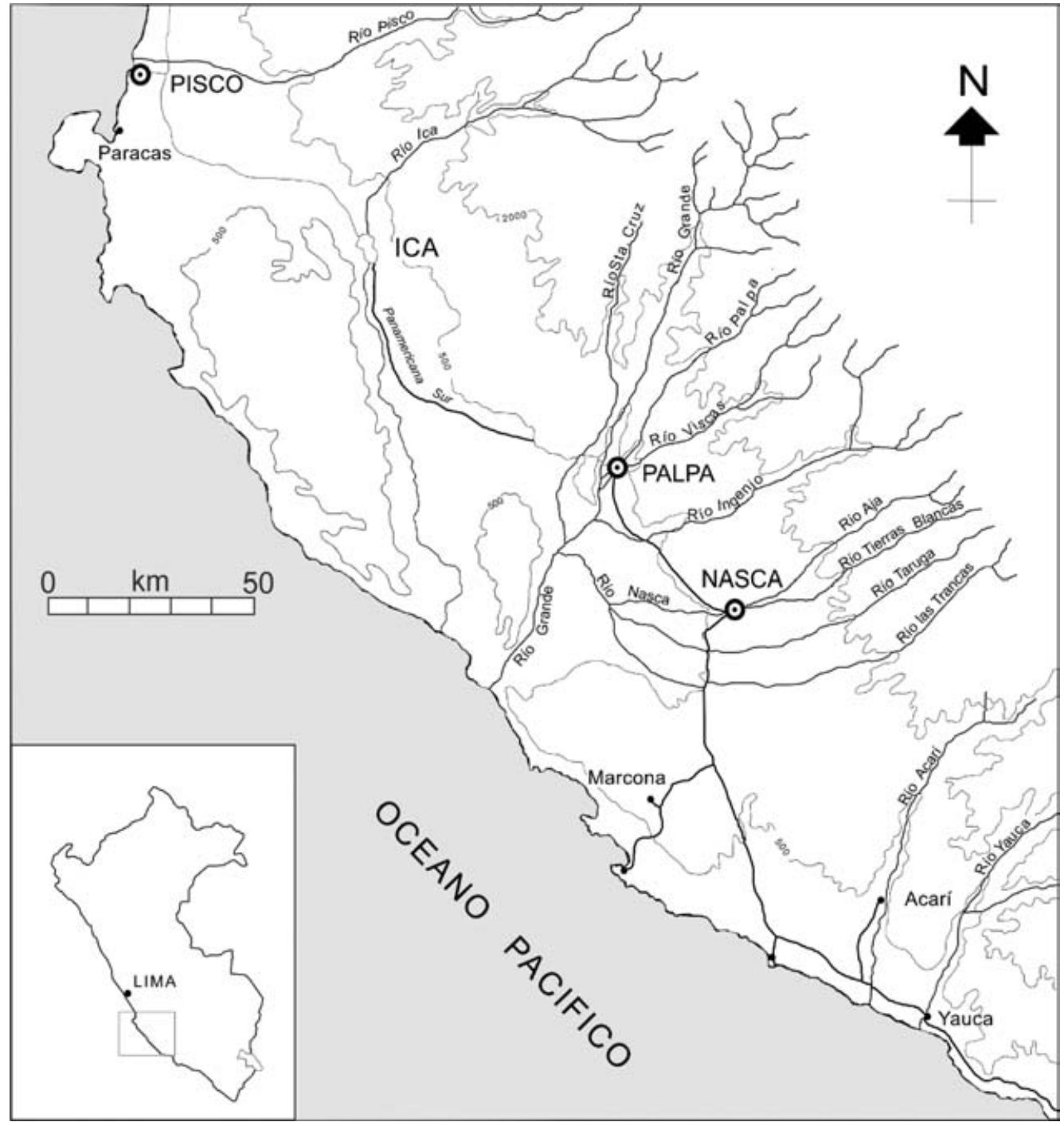

Figure 1. Map of south-western coastal Peru showing the towns of Palpa and Nasca in the desert regions near rivers draining the highlands to the east.

are numerous and encompass many local styles, but their use as geo-chronological markers is problematic. This is because the lines can be either older or younger than the pottery itself depending upon the circumstances at the find locations(Hawkins 1967). One early approach was made through a comparison of the designs found on pottery of known age in the region with the designs of the geoglyphs themselves. The best match was suggested to be the designs on Nasca Style 3 and 4 pottery, which confined the age to the Early Intermediate Period dated to between $100 \mathrm{BC}$ and AD 350 (Hawkins 1967), equivalent to 2100-1650 years ago. More recent finds of pottery by Johny Isla of the Nasca-Palpa project associated with the geometric geoglyphs at Sacramento and San Ignacio near Palpa 
are attributed to styles of Nasca ceramics with a time range of $\mathrm{AD} 200-650$, using correlation with ${ }^{14} \mathrm{C}$ ages of nearby contexts containing those styles (J. Isla pers. comm.).

Other attempts to directly date the geoglyphs using the age of diagnostic pottery fragments found on cleared surfaces lines have suggested a range of times that different geoglyphs were produced. In the seminal study using this approach (Silverman $\&$ Browne 1991), the areas near Palpa and those further south in the Ingenio River valley were studied. In both areas the great majority of diagnostic pottery fragments that were closely associated with geoglyphs were classified as Nasca ceramics from the Early Intermediate Period (200 BC to AD 600). However, a small number of sites in each area had fragments of much earlier Early Horizon 10 pottery (800-200 BC) or much later Late Intermediate Period (AD 1000-1476) style ceramics. In that study they assumed that the presence of a particular period's pottery indicated use of the geoglyph in that period, and that the earliest pottery on a site indicates the time at which, or before which, the geoglyph was first elaborated. Finally, AMS ${ }^{14} \mathrm{C}$ ages were obtained on organic matter (lichens, cyanobacteria or fungi) beneath rock varnish on nine stones removed from cleared areas by the line-builders(Clarkson \& Dorn 1992; Dorn et al. 1992). Calibrated ages ranged from $190 \mathrm{BC}$ to $\mathrm{AD} 600$, equivalent to $1400-2200$ years ago. However, the work of Dorn using this method on these materials has recently been called into question (Beck et al. 1998).

To overcome these disparities we have employed optically stimulated luminescence (OSL) dating on the sediments within the lines themselves. This method allows the burial age of the sediments to be obtained (Huntley et al. 1985), thus providing an absolute minimum age for the construction of the geoglyph. The sample collection, preparation and dating methods were based on standard protocols for OSL dating (Murray \& Wintle 2000). Eight OSL ages for the lines and surrounding geological features were obtained.

\section{Sampling and analysis}

Our study areas (Figure 2) lie immediately north and south of the town of Palpa, about $16-20 \mathrm{~km}$ north-north-west of the major concentration of the Nasca Geoglyphs. Both the Sacramento and San Ignacio sites occur on the flat upper surfaces of elevated elongate colluvial pediments (locally referred to as mesetas) that are separated by valleys that drain the higher mountain areas to the east. Figures 3 and 4 show our sample locations on plots of the criss-crossing array of lines and trapezoidal features exhibited at both of these sites.

Optical luminescence dating is a technique that is greatly improved over old thermoluminescence dating methods on sediments, and is applied for the first time to the problem of dating stone lines in this paper. The ages obtained correspond to the last time the sediment grains were exposed to light. The buried grains record the effects of natural radiation which is detected by their subsequent light emission in the lab. This measurement yields the radiation dose in the grains during burial (the equivalent dose). The rate of natural irradiation in the burial environment (dose rate) is assessed on site by collecting sediment samples and analysing them for their radioactive element content, or by direct measurement of the dose rate within the sediment itself. The details of the dating approach from an archaeologist's perspective are outlined in Rink (2000), and the physical basis of the method is given in Rink (2003). 


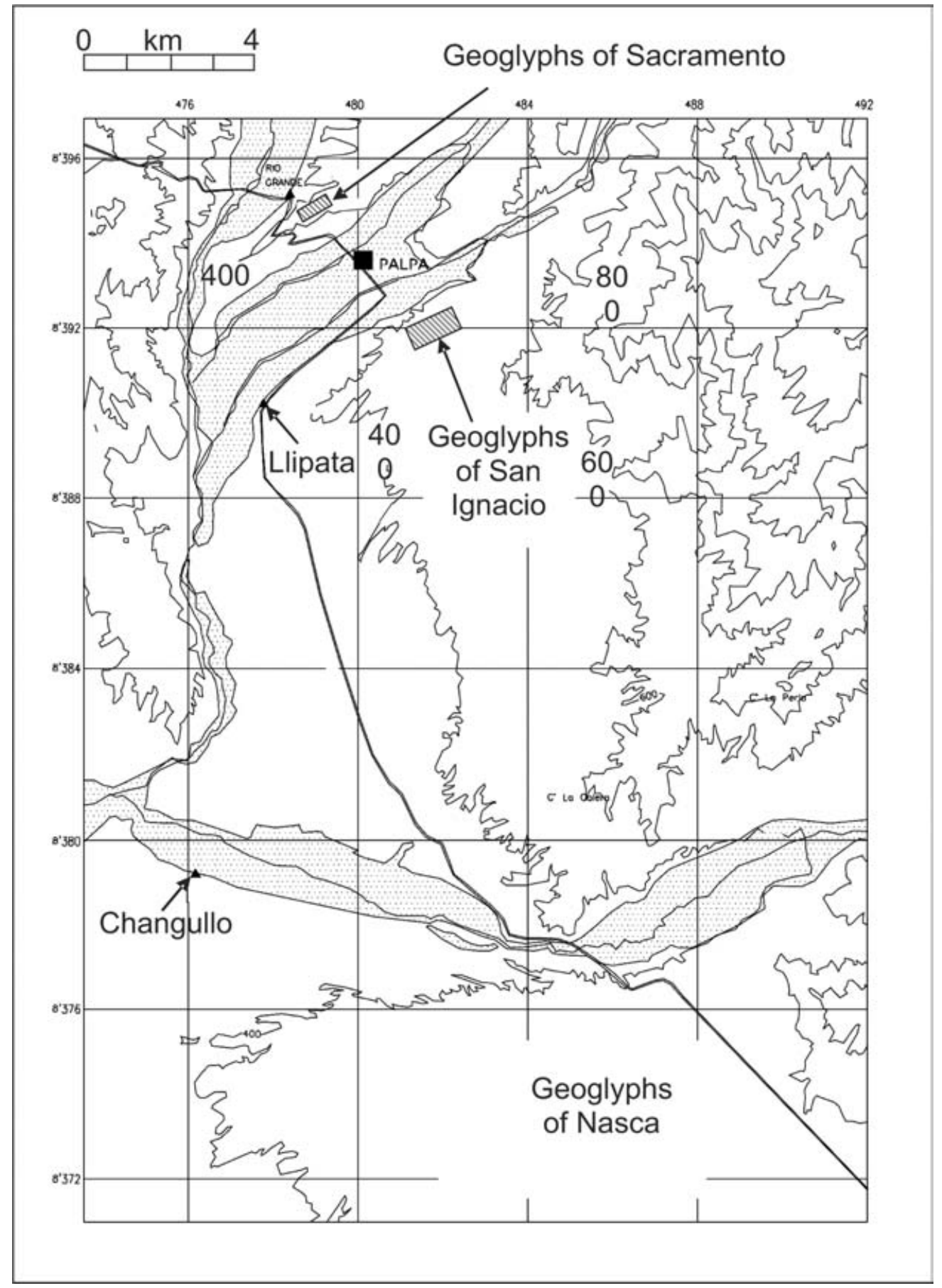

Figure 2. Topographic map of the region near Palpa showing the study locations and the relationship to the main area of the Nasca geoglyphs. The hachured areas correspond to the mapped areas in Figures 3 and 4. Elevation contours in metres above sea level. 


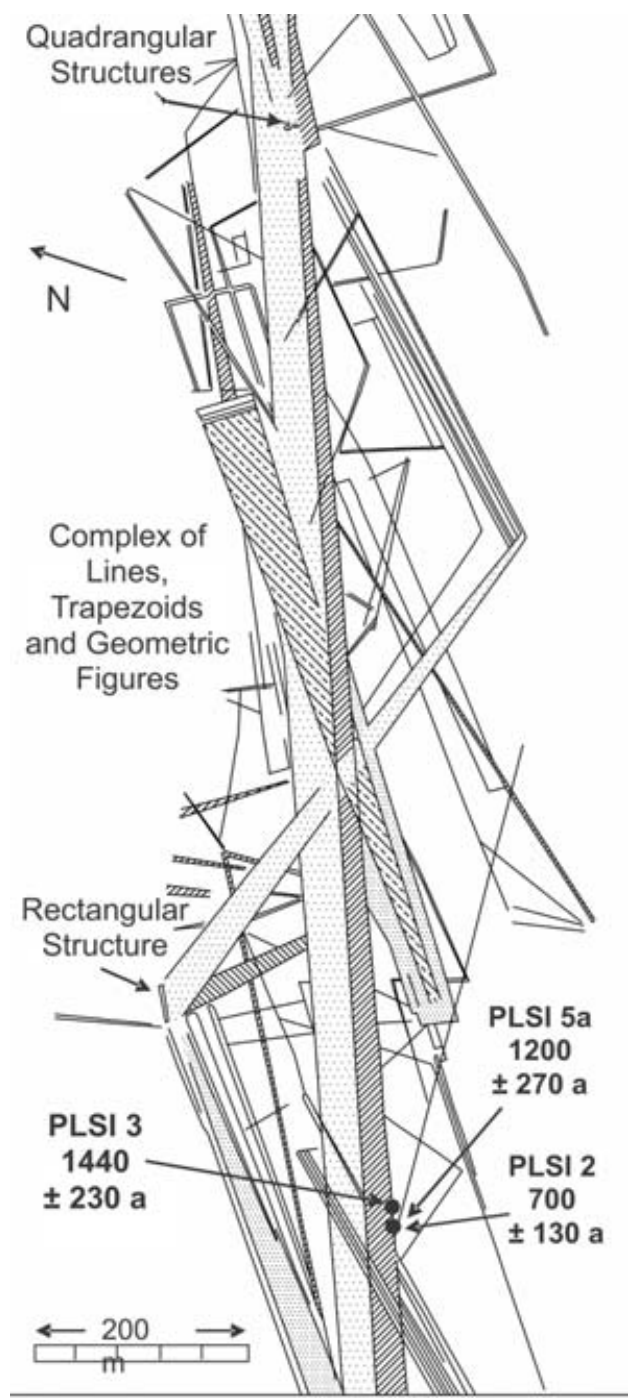

Figure 3. Geometric geoglyphs found on the San Ignacio meseta. Sample names (PLSI) and OSL ages are also shown, base map after Figure 1 of Reindel et al. (2002).
Sample names were given based on their locality: PLSI (San Ignacio meseta, Figures 2 and 3) and Sac (Sacramento meseta, Figures 2 and 4). Two of the samples from San Ignacio (PLSI2, PLSI5a) were collected from the walls of a trench cut transversely through the 1.5-2m wide stone line (Figure 5). A third sample (PLSI5b) was taken from the floor of the trench once excavated at night down to the desert surface. The fourth (PLSI3) was taken from beneath a large stone near the centre of the same stone line about $15 \mathrm{~m}$ north-east of the trench. Two of the Sac samples (Sac 1 and Sac 3) were situated in stone lines on opposite sides of a single trapezoid (Figure 4). They were collected by making vertical holes into the stone line. The third sample (Sac 4) was collected from beneath a large stone in the stone line on the same side of the trapezoid as Sac 1, some $200 \mathrm{~m}$ away. Finally, a sample of the undisturbed desert surface outside of geoglyphs (Sac 7) was taken by driving a plastic tube horizontally into a small vertical profile at a depth of $6-8 \mathrm{~cm}$ from the surface. To determine the local radiation dose rates from gamma and cosmic rays, we emplaced thermoluminescence dosimeters at all locations where sediments were extracted, except for samples PLSI5a and PLSI5b where U, Th and $\mathrm{K}$ analysis of the sediments were used to calculate the gamma dose rate using published tables (Adamiec \& Aitken 1998), and the cosmic dose rate was calculated using published data (Prescott \& Hutton 1994).

All samples were collected at night using low-intensity red light to prevent daylight exposure of the extracted sediment. Grains of K-feldspar and quartz were prepared in low orange light conditions using a combination of wet sieving, chemical treatments and heavy liquid separations (see end note).

\section{Results}

At the San Ignacio meseta four samples were dated by OSL (Figures 2 and 3, Table 1). Ages from the trenched area within the built stone line ranged from $1200 \pm 270$ years ago at its 


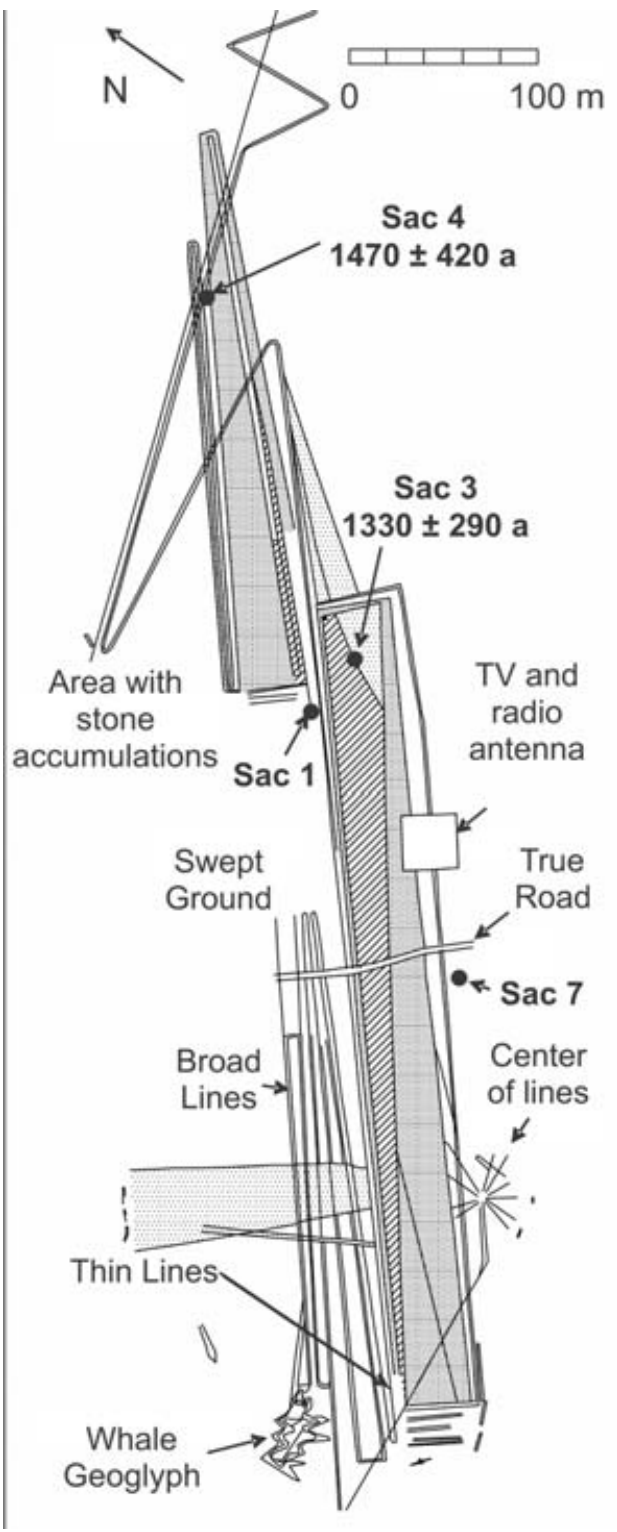

Figure 4. Geometric geoglyphs found on the Sacramento meseta. Sample names (Sac) and OSL ages are shown, base map after Figure 11 of Reindel et al. (1999). base just above the original desert surface, to $720 \pm 130$ years ago for a position about $100 \mathrm{~mm}$ higher in the stone line, but $300 \mathrm{~mm}$ below its surface. A sample taken in the trench location from below the original desert surface yielded a much older age of $>5300$ years ago. The fourth sample (PLSI3) was taken about $250 \mathrm{~mm}$ below the top of a large stone on the crest of the same stone line, in a location about $15 \mathrm{~m}$ north-east of the trench location on the crest of the same stone line. It yielded an age of $1440 \pm 230$ years ago.

Four OSL ages were also obtained at the Sacramento site (Figures 2 and 4, Table 1). Two samples yielded ages in close agreement with each other: Sac 4 (from beneath a large stone) gave $1470 \pm 420$ years ago and Sac 3 (from a stone accumulation pile) gave $1330 \pm$ 290 years ago. Another sample (Sac 1) from a stone accumulation pile gave a much older age of $2380 \pm 390$ years but the small number of aliquots, the strong scattering of the $D_{\mathrm{e}}$ values (Figure 7) and the problematic preheat plateau data (Figure 6) provide little confidence in this result. The sample of the undisturbed desert surface $(60-80 \mathrm{~mm}$ depth) gave an age of about 12000 years, which strongly suggests the source of the grains was mainly in situ breakdown of partially exposed rock fragments or downward movement of grains into the desert pavement that had been exposed to light by much earlier events. Figure 8 presents a graphic summary of the dating results.

Studies of the sediments taken within $3 \mathrm{~mm}$ of the bottom of the large stone at Sac 4 showed very large doses of 20-40Gy, consistent with contamination of the sediments with grains resulting from the breakdown of the large stone immediately above. Aliquots with these large doses were excluded from the age calculation.

\section{Discussion}

Our samples come from several different kinds of geological contexts and thus require different interpretations in relation to how their ages are related to cultural activity. The 


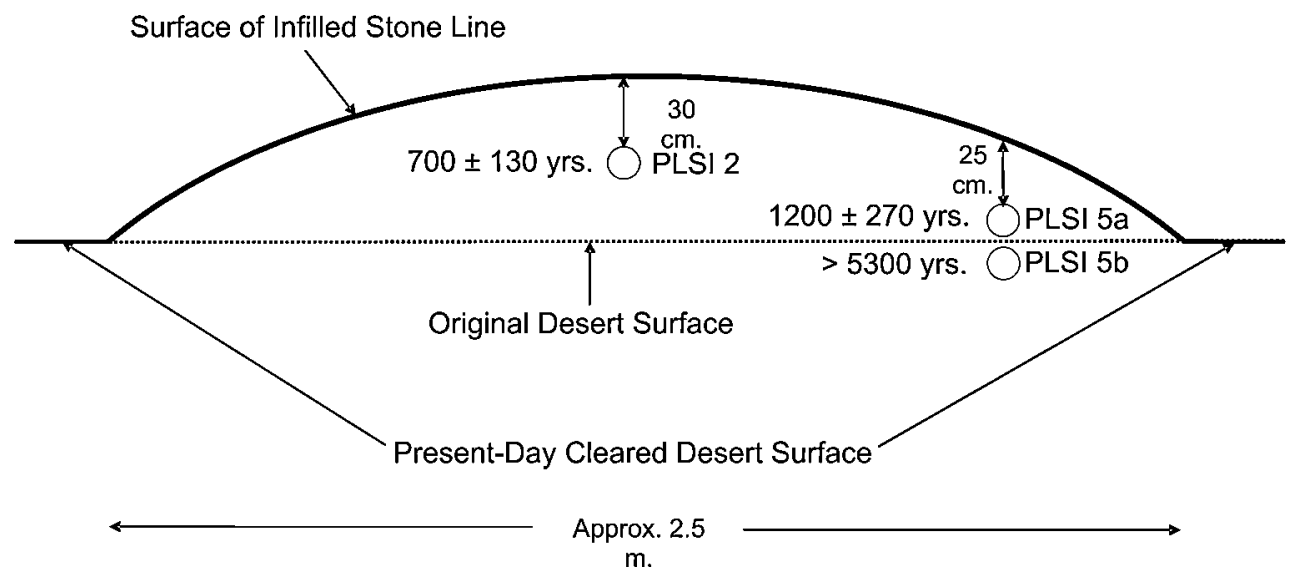

Figure 5. Schematic cross section of trench wall made at San Ignacio into a stone line. Locations of OSL samples and ages are shown.

samples collected from beneath large stones (PLSI3 and Sac 4) would have been trapped below them at the time the stones were emplaced, thus they potentially provide an age estimate related to the time that the sediments at the desert surface were buried. Those sediments right at the surface would have had a zero age at that time. The samples taken from within the stones piled up to make the stone lines (PLSI2, PLSI5a, Sac 1 and Sac 3) are interpreted as sediment infill and would represent aeolian sediments that were deposited into the voids in the stone pile after it was constructed. The samples below the infill within the stone line (PLSI5b), were sourced in sediments near to but below the original surface of the desert, and thus (as seen from the results) were not fully zeroed near the time of emplacement of the stones on the cleared surface above. Finally the sediments collected below the undisturbed desert surface (Sac 7) at a location away from the stone lines represent sediments that have not recently been buried, but are probably in part produced by the direct physical weathering of larger elements to produce sand size particles within the subsurface of the desert.

For these differing contexts described above, only one that has been dated can be directly related to a cultural activity: the placement of a large stone into the pile. For the two sediments collected in this context, both yielded reasonable ages for the placement of the stones by humans, and they were very similar to each other, even though they were from widely separated geoglyphs. For the sediment infill samples at PLSI, we found dating evidence that the period of aeolian infill either continued for several hundred years, or there may have been a deflational episode and subsequent later infill event represented by the younger ages near the top of the sequence. For the Sac samples one sediment infill sample provided an age in close agreement with the older of the two at PLSI, while one other yielded anomalous results. For samples from the contexts near or below the desert surface, we obtained much older ages than any of the others from infill or below large stones, consistent with what would be expected from unzeroed or partially zeroed sediments in those locations, essentially undisturbed by human activity or recent deflation. The relationship between pottery fragment occurrence in the various contexts, with respect to their significance to the age of the geoglyphs, is discussed further below. 
Table 1. OSL ages, analytical data and dose rates

\begin{tabular}{|c|c|c|c|c|c|c|c|}
\hline Sample & $D_{\mathrm{e}}(\mathrm{Gy})$ & $\mathrm{U}(\mathrm{ppm})$ & Th (ppm) & $\mathrm{K}(\%)$ & $D_{\beta}(\mathrm{mGy} / \mathrm{a})$ & $\begin{array}{l}D_{y}+D_{\text {cos }} \\
(\mathrm{mGy} / \mathrm{a})\end{array}$ & $\begin{array}{c}\text { Age } \\
\text { (years ago) }\end{array}$ \\
\hline Sacl & $9.84 \pm 1.5$ & $3.63 \pm 0.1$ & $12.05 \pm 0.32$ & $2.19 \pm 0.09$ & $2.415 \pm 0.198$ & $1.721 \pm 0.086$ & $2380 \pm 390$ \\
\hline Sac3 & $5.48 \pm 1.14$ & $3.77 \pm 0.1$ & $11.46 \pm 0.3$ & $2.26 \pm 0.11$ & $2.484 \pm 0.216$ & $1.628 \pm 0.081$ & $1330 \pm 290$ \\
\hline $\begin{array}{l}\text { Sac4 } \\
\quad(3 \mathrm{~mm}-3 \mathrm{~cm})\end{array}$ & $5.87 \pm 1.67$ & - & - & - & $2.440 \pm 0.199^{7}$ & $1.561 \pm 0.078$ & $1470 \pm 420$ \\
\hline $\mathrm{Sac} 7 \mathrm{~b}$ & $49.47 \pm 2.88$ & - & - & - & & - & $\approx 12000^{9}$ \\
\hline PLSI2 & $3.03 \pm 0.7$ & $4.96 \pm 0.1$ & $14.47 \pm 0.34$ & $1.93 \pm 0.08$ & $2.449 \pm 0.218$ & $1.757 \pm 0.088$ & $720 \pm 130$ \\
\hline PLSI3 & $6.00 \pm 0.89$ & - & - & - & $2.362 \pm 0.197^{8}$ & $1.813 \pm 0.091$ & $1440 \pm 230$ \\
\hline PLSI5a & $4.71 \pm 1.04$ & $3.45 \pm 0.1$ & $10.14 \pm 0.28$ & $2.117 \pm 0.09$ & $2.293 \pm 0.188$ & $1.647 \pm 0.082^{10}$ & $1200 \pm 270$ \\
\hline PLSI5b & $>22$ & - & - & - & & - & $>5300^{9}$ \\
\hline
\end{tabular}

1 Preparation: quartz separates were etched with 49 per cent $\mathrm{HF}$ for $40 \mathrm{~min}$ to remove the alpha-irradiated outer rinds followed by 48 per cent $\mathrm{HBF}_{4}$ treatment and final wet sieving. Preliminary tests on K-feldspar sand grains showed extensive fading after laboratory irradiation, precluding their use in age determinations. Quartz equivalent doses in single aliquots (8mm diameter) were determined using the SAR protocol (Murray \& Wintle 2000) on quartz sand grains (90-125 $\mu \mathrm{m}$ size) that made up $<1$ per cent of all samples. Plots of preheat temperature as a function of equivalent dose $\left(D_{\mathrm{e}}\right)$ were made for most samples (Figure 6). Due to the extremely small amounts of quartz available, and generally weak signals, many of the aliquots used in constructing histograms of the distribution of $D_{\mathrm{e}}$ (Figure 7) were the same aliquots used to determine the preheat temperature range (plateau) appropriate to $D_{\mathrm{e}}$ determination using the SAR protocol (selected ranges are given in Table 2). The $D_{\mathrm{e}}$ for the age determination was conservatively taken as the mean of all aliquots in the lower dose range of the histogram that were clearly separated by a gap in the $D_{\mathrm{e}}$ 's at higher dose ranges that had most likely been partially zeroed, or had been derived from the breakdown of rock fragments. The range of $D_{\mathrm{e}}$ 's used in each age determination are also shown in Table 2. The burial age was calculated as the ratio of the $D_{\mathrm{e}}$ to the total annual radiation dose (beta, gamma and cosmic).

2 A moisture content of: $0 \pm 5$ per cent was assumed for the dose rate calculations.

$3 \mathrm{U}, \mathrm{Th}, \mathrm{K}$ were determined using neutron activation analysis.

$4 D_{\gamma}+D_{\text {cos }}$ results from TLD measurements.

$5 D_{\beta}$ is based on NAA analysis of sediments using published dose rate tables.

6 The age and error estimate was calculated using the program 'data' from Rainer Grün, Australian National University.

$7 D_{\beta}$ for Sac 4 was calculated using the average of the U-, Th-, and K-content of Sac 1 and Sac 3, because there are no NAA data for Sac 4.

$8 D_{\beta}$ for PLSI3 was calculated using the average of the U-, Th-, and K-content of PLSI2 and PLSI5a, because there are no NAA data for PLSI3.

9 A total dose rate of $4.1 \mathrm{mGy} / \mathrm{a}$ was assumed for the age estimation.

10 There are no TLD values for sample PLSI5a. $D_{\gamma}$ was calculated using the U-, Th-, and K-values from NAA. $D_{\text {cos }}$ of $0.213 \mathrm{~m}$ Gy/a for a depth of $30 \mathrm{~cm}$ was calculated using the program 'data' from Rainer Grün, which uses cosmic dose rate determinations based on published data.

\section{Method}




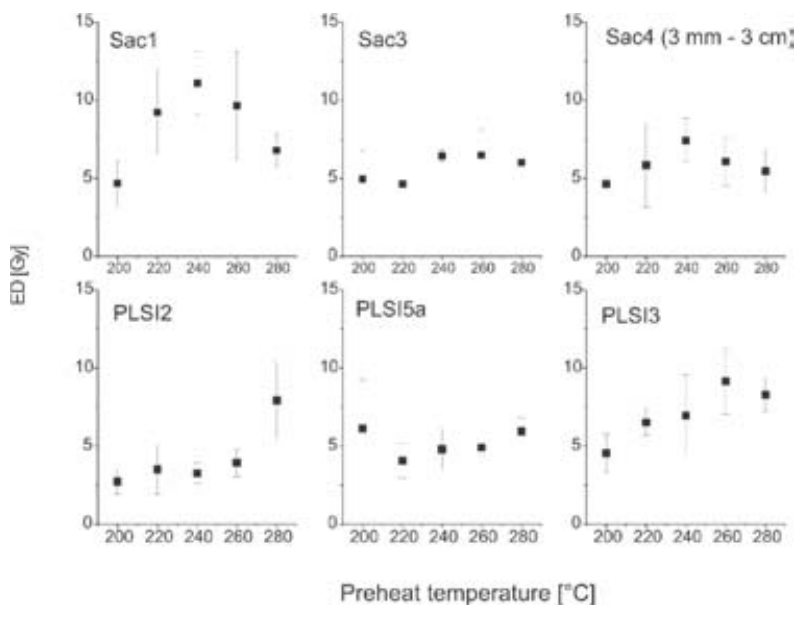

Figure 6. Preheat plateau tests for six of the samples dated in this study.

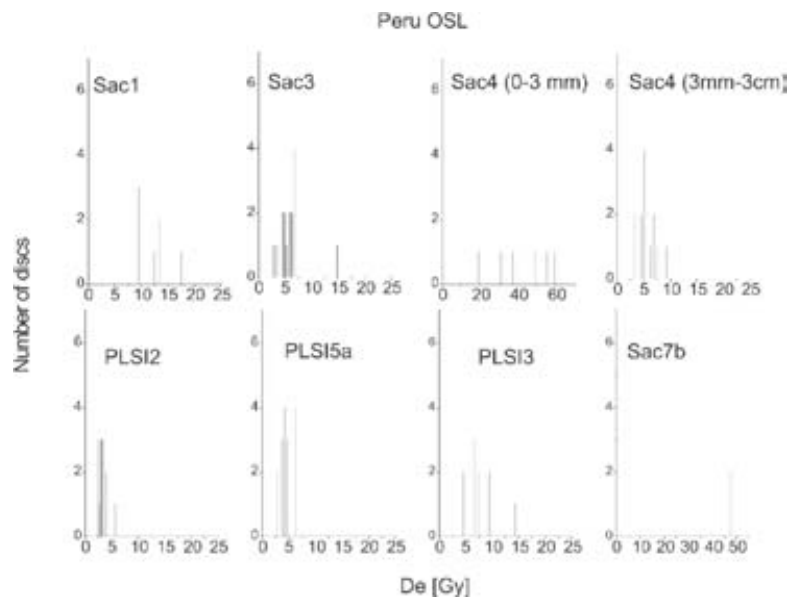

Figure 7. Histograms showing the frequency distribution of equivalent doses found for all single aliquots for each sample dated.
Both the emplacement of large stones and the infill of sediment into artificial structures of larger stones are dated in our approach. The emplacement age of large stones at each of the two geoglyphs agree. This can be taken as the time of geoglyph construction: within a period extending from about 200 years before and after about $\mathrm{AD} 600(1400 \pm 200$ years ago). For the case of sediment infill, the time the stones were emplaced must predate this time because the sediment infill must be later than the time of stone emplacement. The infill of the wall-like structure at San Ignacio (PLSI3, PLSI5a samples) was dated to $\mathrm{AD} 561 \pm 230$ and AD $801 \pm 270$. Therefore the structure must have been built sometime before $\mathrm{AD} 561$ within the ranges of uncertainty. The age of $720 \pm 130$ years ago for sediments higher in the stone structure suggests that this infill process continued for a significant length of time, or there was a deflation event followed

Table 2. Equivalent dose determination data

\begin{tabular}{lcccc}
\hline \multicolumn{1}{c}{ Sample } & Preheat range $\left({ }^{\circ} \mathbf{C}\right)$ & $\begin{array}{c}\text { Histogram range } \\
\text { for De }(\mathbf{G y})\end{array}$ & $\begin{array}{c}\text { Number of aliquots } \\
\text { used for } D \mathbf{e}^{1}\end{array}$ & $D_{\mathbf{e}}(\mathrm{Gy})^{2}$ \\
\hline Sac 1 & $220-240$ & $9.3-10.2$ & 5 & $9.84( \pm 1.5)$ \\
Sac 3 & $200-280$ & $2.9-6.8$ & 19 & $5.48 \pm 1.14$ \\
Sac 4 (3mm-3cm) & $220-240$ & $3.3-9.4$ & 17 & $5.87 \pm 1.67$ \\
Sac 7b & 220 & $47-53$ & 3 & $49.47( \pm 2.88)$ \\
PLSI2 & $220-260$ & $2.1-4$ & 21 & $3.03 \pm 0.7$ \\
PLSI3 & $220-240$ & $4.8-7.5$ & 12 & $6.00 \pm 0.89$ \\
PLSI5a & $220-240$ & $2.7-6.4$ & 21 & $4.71 \pm 1.04$ \\
PLSI5b & 240 & - & 1 & $>22$ \\
\hline
\end{tabular}

1 Only aliquots with recycling ratios between 0.85 and 1.15 were used.

2 The standard deviation of all the aliquots in the stated histogram range is used as the error value for all data except for Sac 1. For Sac 1 the SD is only 0.4. This number seems too small in comparison to the other samples and under consideration that four larger values were removed for the $D_{\mathrm{e}}$ calculation of this sample. Therefore, an error of about 15 per cent was estimated. In any case this sample was not considered a good age estimate for burial of the sediment because of the poor preheat plateau (see text). 


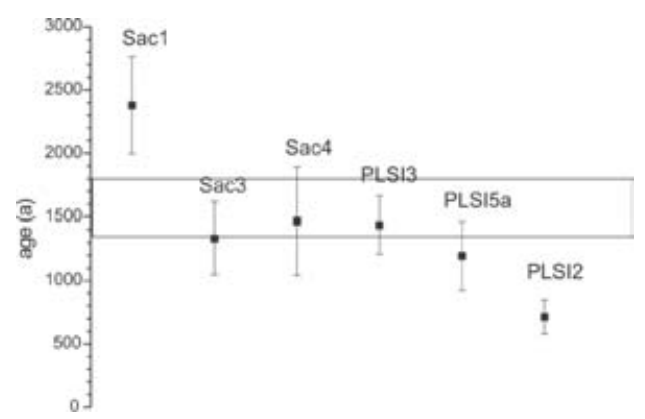

Figure 8. Graphic summary of the dating results. The results of samples taken from beneath the original desert surface are not shown. The rectangle symbolises the age range of the associated pottery fragments and therefore the expected age range from an archaeological point of view. by a later sedimentation at that time. In any case it is recommended to take samples from the lowest sediment level within the stone structure in order to get as close as possible to the date of the actual building of the structure. The ages of sediment infill at Sacramento (Sac3, Sac4) of AD $671 \pm 290$ and $\mathrm{AD} 531 \pm 420$ are in close agreement with the ages of infill at San Ignacio. These geoglyphs must then have been built about the same time. The good agreement of individual ages found at each site from different contexts (under large stones as opposed to within areas of smaller stones) shows that both types of sampling provide consistent estimates of burial age of the sediments. It also shows that the infill process for the lower levels of the stone structures and for relatively well-shielded sites (underneath large stones) must have been relatively fast and non-reversible.

Apparent ages of about 12000 years ago for $60-80 \mathrm{~mm}$ below the undisturbed desert surface, and an age of about 5300 years ago for the uppermost desert surface below a stone line, clearly indicate that the upper desert surfaces contain grains that were either derived from partially zeroed rock fragments breaking down at the desert surface and then moving downward, or the slow reworking of fully-zeroed grains downward into the surface. A strong indication that breakdown of stone surfaces does occur is provided by the evidence of grains carrying 20-40Gy in sediments within $3 \mathrm{~mm}$ from the lower surface of a large stone (Sac 4). These results give some indication that further OSL studies could provide information about the activity of desert surfaces.

Pottery fragments found by Johnny Isla of the Nasca-Palpa project in close association with the geoglyphs during excavations at both San Ignacio and Sacramento were Nasca ceramics attributed to the time range of 1800-1350 years ago (AD 200-650). The minimum ages for construction of the geoglyphs based on OSL are about 1500 to about 1200 years ago (AD 500-800). These generally correspond well with the younger end of the pottery age range of 1350 years ago (compare Figure 8). If we assume that about 50-100 years were required to infill the stone lines, then the correspondence is further improved. For the two geoglyphs studied here, there is no evidence for later occupation or use as represented by pottery of younger age having been found there. If we assume that longer times were necessary to infill the lines, then the older range of the pottery range (1800 years ago) is also consistent with the time of construction of the lines. The age of $700 \pm 130$ years for the younger sediments within the line at San Ignacio do indicate that the latter interpretation is a clear possibility, though we feel this latter hypothesis is far less likely. Considering the large number of 'dust devils' (wind storms) that transport large quantities of sand in the area, it seems geologically unreasonable to imagine the lines not filling with the first $100 \mathrm{~mm}$ of sediment in a short time. The presence of older Nasca ceramics on present-day cleared surfaces could simply result from their presence there at the time the larger stones were removed to build the 
geoglyphs (i.e., the surface was not cleared of all ceramic fragments at that time). On the other hand, the good correspondence between the younger Nasca pottery and the OSL age of infill provides strong evidence that these particular structures were built and frequented by the Nasca people in the later parts of the Early Intermediate Period. Since the latest Nasca style ceramics are known to date to about $\mathrm{AD}$ 600-650, it is doubtful that the construction age extends to the younger parts of the OSL error range (AD 700-850), suggesting that the geoglyphs at San Ignacio and Sacramento that we dated were probably constructed between $\mathrm{AD} 400$ and 650. We also note the close correspondence between our OSL ages and the youngest of the AMS ${ }^{14} \mathrm{C}$ ages of AD 600 (Clarkson \& Dorn 1992; Dorn et al. 1992) on rock varnish on moved stones, though doubt has been cast on that work (Beck et al. 1998). Our results thus show that OSL is an applicable method for the absolute dating of geoglyphs, and the dates correspond well with age estimations based on archaeological results.

\section{Acknowledgements}

We thank J. Isla, who is Co-Director of the Nasca-Palpa project and archaeologist at the Institute Arquelogicos, Lima, for help during fieldwork and for coordinating the production of the maps in Figures 1-4. We also thank the Natural Sciences and Engineering Council of Canada for financial support to WJR.

\section{References}

Adamiec, G. \& M.J. Aitken. 1998. Dose-rate conversion factors: update. Ancient TL 16: 37-50.

Aveni, A.F. 1990. The lines of Nazca. Memoirs American Philosophical Society, vol. 183. Philadelphia: American Philosophical Society.

Beck, W., D.J. Donahue, A.J.T. Tull, G. Burr, W.S. Broecker, G. Banani, I. Hajdas \& E. Malotki. 1998. Ambiguities in direct dating of rock surfaces using radiocarbon measurements. Science 280: 2132-5.

Bray, W. 1992. Under the skin of Nazca. Nature 358: 19.

Clarkson, P.B. \& R.I. Dorn. 1992. Nuevos datos relativos a la antiguedad de los geoglifos y pukios de Nazca, Peru. Boletin de Lima 13: 33-45.

Dorn, R.I., P.B. Clarkson, M.F. Nobbs, L.L. Loendorf \& D.S. Whitley. 1992. New approach to the radiocarbon dating of rock varnish, with examples from drylands. Annals of the Association of American Geographers 82: 136-51.

Grun, A., S. Bar \& S. Beutner. 2000. Signals in the sand: $3-\mathrm{D}$ recording and visualization of the Nasca geoglyphs. Intentional Archives of Photogrammetry and Remote Sensing 33: 3.

Hawkins, G.S. 1967. Prehistoric desert markings in Peru, in P.H. Oehser (ed.). Research reports National Geographic Society: 117-44. Washington, DC: National Geographic Society.
Huntley, D.J., D.I. Godfrey-Smith \& M.L. Thewalt. 1985. Optical dating of sediments. Nature 313: 105-7.

Mejia Xesspe, T. 1927. Acueductos Y Caminos Antiguos De La Hoya Del Rio Grande De Nasca. Lima: Museo de Antropologia.

Morrison, T. 1978. Pathways to the Gods: the mystery of the Andes lines. Salisbury: Michael Russel.

Murray, A.S. \& A.G. Wintle. 2000. Luminescence dating of quartz using an improved single-aliquot regenerative-dose protocol. Radiation Measurements 32: 57-73.

Prescott, J.R. \& J.T. Hutton. 1994. Cosmic ray contributions to dose rates for luminescence and ESR dating: large depths and long-term time variations. Radiation Measurements 23: 97-500.

ReICHE, M. 1969. Mystery on the desert. Stuttgart: Eigenverlag.

Reindel, M., J. Isla \& K. Koschmieder. 1999. Vorspanische Siedlungen und Bodenzeichungen in Palpa, Sud-Peru. Beiträge zur Allgemeinen und Vergleichenden Archäologie, Band 19: 313-81. Mainz.

Reindel, M., J. Isla, A. Grun \& K. Lambers. 2001. Neue Erkenntnisse zu Siedlungen, Bodenzeichnungen und Kultplätzen in Palpa, Süd-Peru: Ergebnisse der Feldkampagne 2000 des Archäologischen Projektes Nasca-Palpa. Jahresbericht der SchweizerischLiechtensteinischen Stiftung für archäologische Forschungen im Ausland 2000. Zürich, Vaduz. 


\section{W.J. Rink \&J. Bartoll}

Reindel, M., J. Isla \& K. Lambers. 2002. Die Arbeiten des Archäologischen Projektes Nasca-Palpa, Peru, im Jahr 2002. Jahresbericht/2002: 119-132. Zürich, Vaduz: Swiss Liechtenstein Foundation for Archaeological Research Abroad.

RINK, W.J. 2000. Beyond ${ }^{14} \mathrm{C}$ dating: a user's guide to long-range dating methods in archaeology, in P. Goldberg, V.T. Holliday \& C.R. Ferring (ed.). Earth sciences and archaeology: 385-418. Berlin: Springer.
-2003. Electron spin resonance and luminescence dating: principles and applications. Physics in Canada 59: 275-84.

Silverman, H. \& D. Browne. 1991. New evidence for the date of the Nazca lines. Antiquity 65: 208-20.

Silverman, H. \& D.A. Proulx. 2002.

The people of America - the Nasca. Oxford: Blackwell. 